\title{
Meningeal and cortical grey matter pathology in multiple sclerosis
}

Bogdan F Gh Popescu ${ }^{1,2}$ and Claudia F Lucchinetti ${ }^{3^{*}}$

\begin{abstract}
Although historically considered a disease primarily affecting the white matter of the central nervous system, recent pathological and imaging studies have established that cortical demyelination is common in multiple sclerosis and more extensive than previously appreciated. Subpial, intracortical and leukocortical lesions are the three cortical lesion types described in the cerebral and cerebellar cortices of patients with multiple sclerosis. Cortical demyelination may be the pathological substrate of progression, and an important pathologic correlate of irreversible disability, epilepsy and cognitive impairment. Cortical lesions of chronic progressive multiple sclerosis patients are characterized by a dominant effector cell population of microglia, by the absence of macrophagic and leukocytic inflammatory infiltrates, and may be driven in part by organized meningeal inflammatory infiltrates. Cortical demyelination is also present and common in early MS, is topographically associated with prominent meningeal inflammation and may even precede the appearance of classic white matter plaques in some MS patients. However, the pathology of early cortical lesions is different than that of chronic MS in the sense that early cortical lesions are highly inflammatory, suggesting that neurodegeneration in MS occurs on an inflammatory background and raising interesting questions regarding the role of cortical demyelination and meningeal inflammation in initiating and perpetuating the disease process in early MS.
\end{abstract}

\section{Review}

Multiple sclerosis (MS), a chronic idiopathic inflammatory demyelinating disease, is the most common cause of nontraumatic disability in young adults [1]. Focal areas of demyelination and relative axonal preservation on a background of inflammation and gliosis represent the pathological features of MS [2,3].

Historically, MS has been considered a disease primarily affecting the CNS white matter and its pathological features were beautifully described and illustrated by Professor Jean-Martin Charcot, an illustrious French neurologist and pathologist, in his famous "Lectures on the Diseases of the Nervous System" delivered at the Salpêtrière in 1868 [2]. In lecture VI, entitled "Disseminated Sclerosis. Pathological Anatomy", besides acknowledging the involvement of the cerebral and cerebellar white matter, deep grey matter, brainstem, and spinal cord white and grey matter, Professor Charcot also pointed to the existence of the cortical

\footnotetext{
* Correspondence: lucchinetti.claudia@mayo.edu

${ }^{3}$ Department of Neurology, Mayo Clinic, 200 First Street SW, Rochester, MN 55905, USA

Full list of author information is available at the end of the article
}

demyelinated lesions: “...the patches are very rarely found on the grey substance of the convolutions" [2]. Because of their poor visualization when using conventional histological methods [4], the study of cortical lesions has largely been disregarded although early postCharcot neuropathological studies have increasingly recognized the involvement of grey matter in MS $[5,6]$.

While white matter lesion load has been able to explain only part of the clinical deficits seen in MS patients, cognitive impairment and seizures could be better explained by pathological processes affecting the grey matter [7-14]. It has also been shown that immunohistochemical techniques are superior to classical myelin histochemical staining methods (luxol fast blue) for detecting cortical demyelinating lesions [4]. Moreover, even among immunohistochemical markers for various myelin proteins, the use of antibodies specific to major myelin proteins is superior to antibodies against minor myelin proteins at detecting cortical demyelination. Therefore, armed with a clinical rationale and with the means to pathologically detect cortical lesions, the last decade has witnessed a surge in the interest allocated to cortical demyelination in MS and represented a 
"golden age" not only for neuropathological, but also for imaging and clinical studies on MS cortical pathology. Recent imaging and pathological studies have indeed confirmed that cortical demyelination is common in MS and more extensive than previously appreciated [4,15-21].

\section{Classification}

The first pathological classification of cortical lesions has been proposed by Kidd et al. [17]. Seven cortical demyelinated lesion types have been described based on their location relative to the venous supply of the cerebral cortex. Type 1 lesions affect both the deep grey matter layers and the subadjacent white matter. Type 2 lesions involve all cortical layers without affecting the underlying white matter. Type 3 lesions involve only the upper cortical layers. Type 4 lesions only involve the subcortical U fibers. Type 5 lesions affect all grey matter layers as well as the subcortical white matter. Type 6 lesions are small demyelinated lesion that can occur in any part of the cortex. Type 7 lesions extend on both banks of a gyrus with or without involvement of the subcortical white matter. The majority of lesions (types 1,4 and 5) arise within the territory of the principal vein [17], whose course begins in the white matter and passes through the cortex [22]. The remaining lesions are located in the territory drained by its branches or in the territory of the superficial veins [17].

A simpler classification has been proposed by Peterson et al. and is based on the location of the cortical demyelinated lesions within the layers of the cortical grey matter $[4,16]$. Studying autopsy material from patients with chronic MS, the authors described four cortical lesion types $[4,16]$. Type I lesions, also called leukocortical lesions, involve the deeper layers of the grey matter as well as the subadjacent white matter at the grey/white matter junction with sparing of the superficial layers of the cortex (Figure 1A). Type II lesions, or intracortical lesions, are small demyelinated lesions centered on blood vessels and confined within the cortex, with sparing of both the superficial cortex and the white matter (Figure 1B). Type III lesions extend from the pial surface into the cortex, most often reaching the cortical layers 3 or 4 (Figure 1C). Type IV lesions extend to the entire width of the cortex without entering the subcortical white matter (Figure 1D) $[4,16]$. Type III and IV lesions are referred to as subpial lesions and can involve multiple adjacent gyri (general subpial demyelination) $[4,16]$. Subpial, intracortical and leukocortical demyelinating lesions have also been described in the cerebellar cortex and hippocampus [23-26].

While the latter classification is widely accepted currently, there are cortical demyelinated lesions that are unaccounted for by the present classification, highlighting the still incomplete understanding of their origin and evolution. We consider lesions affecting all 6 cortical layers with only marginal involvement of the white matter as subpial, rather than leukocortical demyelinated lesions [27]. Their subpial nature is supported by the centrifugal extension of the lesion from the pial surface into the cortex; the involvement of all cortical layers; the vast area of demyelination within the cortex with only limited involvement of the subcortical white matter; and the fact that the center of the lesion is in the grey and not in the white matter [27] as most often reported for leukocortical lesions $[4,16]$. How to classify a cortical lesion involving the whole grey matter width as well as a considerable region of the subadjacent white matter becomes even more complicated, and, theoretically, any of the following possibilities is feasible: a subpial lesion that extends into the white matter; a white matter lesions that extends into the cortex eventually reaching the pia; the coalescence of a subpial lesion with a white matter lesion; or the coalescence of a subpial lesion with a leukocortical lesion. While sometimes there are pathological cues that help in inferring the evolution of such a lesion [28], it is clear in most cases that its dynamics cannot be deduced from only one snapshot in the lesion's development that pathology offers.

\section{The Pathology of Cortical Demyelination and Meningeal Inflammation in Chronic Progressive MS}

The most extensive cortical demyelination has been detected in the cingulate gyrus (Figure 2A), frontal (Figure $2 \mathrm{~B}$ ), temporal, insular and cerebellar cortices, as well as in the hippocampi (Figure 2C) of patients with progressive MS, while the paracentral lobule and the occipital lobe are less frequently affected but not spared (Figure 2D) [16,18,23-26,29]. Subpial demyelination preferentially involves the sulci suggesting that it may be induced by stagnant cerebrospinal fluid mediators [4]. Pathological studies have shown that cortical demyelination is prominent and extensive in primary progressive and secondary progressive MS, and in MS patients with cognitive deficits, suggesting it may be the pathological substrate of progression, and an important pathologic correlate of irreversible disability and cognitive impairment $[16,18,25]$.

Similarly to white matter lesions, cortical demyelinated lesions studied in autopsy material from chronic MS patients are well-demarcated, and show oligodendrocyte, axonal and synaptic loss $[4,15,16,20]$. However, other studies described normal synaptic densities in cortical lesions $[25,30]$.

In several other aspects, the pathology of cortical lesions has been reported to be fundamentally different, 


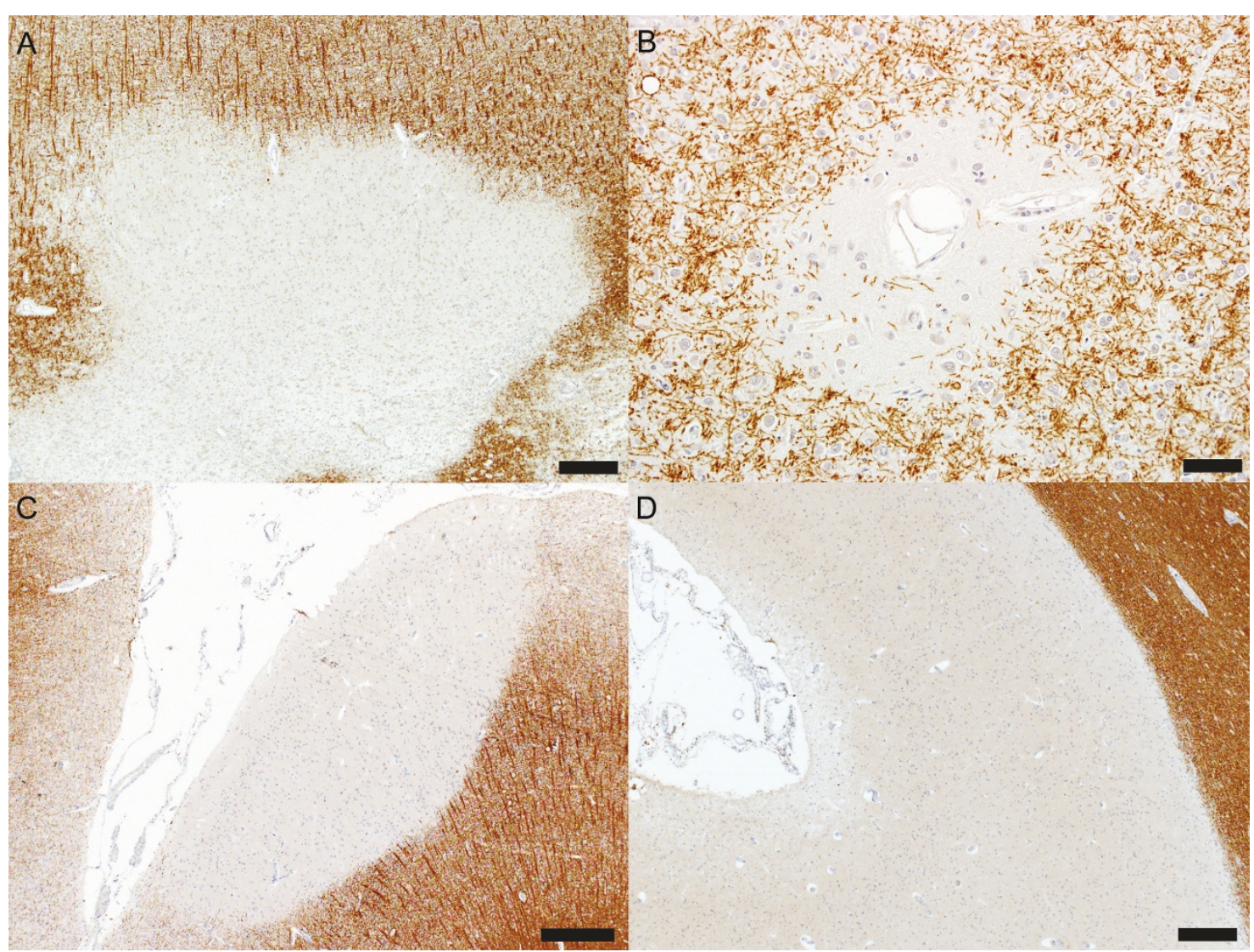

Figure 1 Cortical demyelinated lesion types. (A) Leukocortical lesion (PLP, scale bar = $100 \mu \mathrm{m})$; (B) Intracortical lesion (PLP, scale bar = 500 $\mu \mathrm{m})$; (C) Subpial lesion affecting the superficial cortical layers (PLP, scale bar $=250 \mu \mathrm{m}$ ); (D) Subpial lesion involving all cortical layers without affecting the white matter (PLP, scale bar $=500 \mu \mathrm{m})$.

i.e. cortical demyelinated lesions are less inflammatory than white matter lesions. Purely cortical lesions reportedly lack the lymphocytic and macrophagic inflammatory infiltrates, complement deposition and blood-brain barrier breakdown $[4,15,16]$. Leukocortical lesions are more inflammatory than subpial and intracortical lesions, but less so than lesions in the white matter $[4,15,16,25,30]$. The majority of phagocytic cells in cortical lesions have the morphology of activated ramified microglia that appear in close apposition to neurites and neuronal cell bodies $[4,15,16,25,30]$. Neurons are also damaged as evidenced by neuronal atrophy and apoptosis, and a mild to moderate reduction of neuronal densities in the demyelinated MS cortex $[4,16,20,30]$.

Meningeal inflammatory infiltrates have been extensively characterized in late-stage progressive MS. They are topographically associated with subpial lesions, resemble lymphoid follicular structures, predominate among patients with secondary progressive MS [31,32] and are immunoreactive for Epstein-Barr virus [33]. However, the identification of Epstein-Barr virus infection of meningeal $\mathrm{B}$-cells and its potential role in the pathogenesis of MS remains controversial as these findings have not been confirmed by other studies [34,35]. Furthermore, ectopic B-cell follicle-like structures, topographically associated with subpial lesions, are located in the deep sulci of the temporal, cingulate, insula and frontal cortices of secondary progressive MS patients with accelerated clinical course [36]. Therefore, meningeal inflammatory aggregates are believed to contribute to both cortical demyelination and MS disease progression.

Thus, according to studies that have analyzed cortical pathology in autopsy material from chronic MS patients, cortical demyelination is devoid of inflammatory lymphocytes and macrophages and is driven in part by organized meningeal inflammatory infiltrates $[4,15,16,31,36]$. Corroborated with evidence for neuronal degeneration and glial loss $[4,16,20,30]$, this has led to the suggestion that neurodegeneration in MS proceeds independent of inflammation. However, we have to stress again upon the fact that these studies have relied on post-mortem tissue analysis from MS patients with long-standing, end-stage disease, and that virtually 


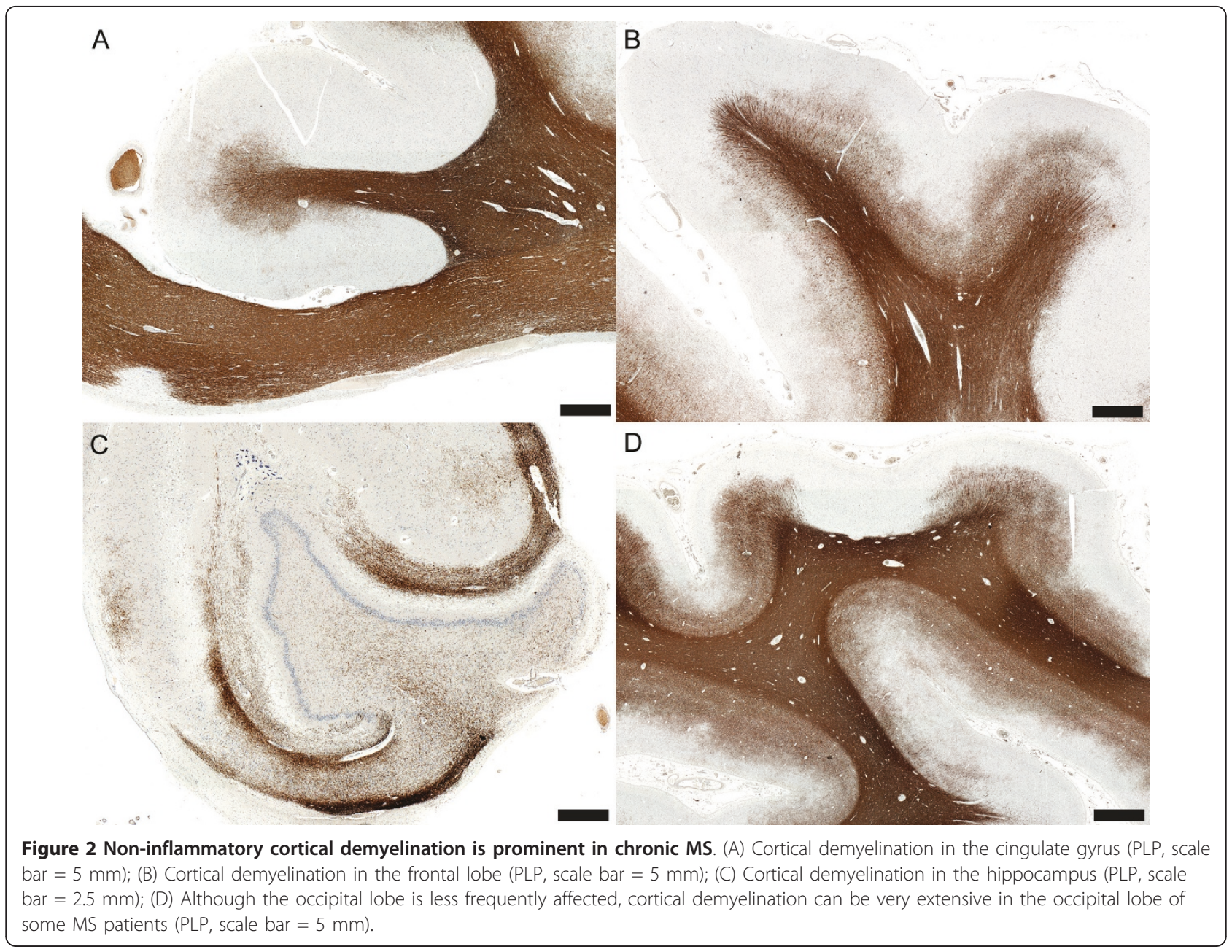

nothing was known about the pathology of cortical demyelination in early MS.

\section{The Pathology of Cortical Demyelination and Meningeal Inflammation in Early MS}

MS may involve the cortex either as classically demyelinated plaques or as neuronal loss and atrophy following retrograde degeneration from white matter lesions [6]. Although cortical lesions could occur secondary to white matter damage $[37,38]$, recent histopathological studies have shown that cortical demyelination may occur spatially removed from and without obvious anatomical relationships to the white matter pathology [39]. Therefore, it is plausible that the cortex could represent an important early and/or initial target of the MS disease process.

MRI has confirmed that cortical lesions and atrophy are already present in early disease $[19,40,41]$ and become more prominent during progressive MS $[7,42]$. Thirty seven percent of patients with clinically isolated syndrome show the presence of cortical lesions [43].
Cortical lesions are more numerous and cortical atrophy is more pronounced in patients with relapsing remitting $\mathrm{MS}$ and cognitive deficits than patients with relapsing remitting MS who do not have cognitive deficits [44]. Relapsing remitting MS patients with epilepsy also have more severe and rapidly evolving cortical lesion load and atrophy compared with relapsing remitting MS patients without epilepsy [45]. Also, a longitudinal MRS study of cortex in relapsing remitting MS has showed periodic peaks consistent with myelin breakdown [46], and increased apparent diffusion coefficients in normal appearing cortex, probably reflecting focal and diffuse cortical damage [40]. Thus, cortical demyelination is already present and common in early MS, and may represent the pathological substrate of cognitive impairment and epilepsy in relapsing remitting MS. Furthermore, MRI evidence of MS cortical onset [41] has been published supporting the hypothesis that cortical demyelination could even represent the earliest pathological event in some MS patients. 
Recent research using brain biopsies obtained early in MS has indeed revealed that cortical demyelination and blood-brain barrier damage also occur early in disease (Figure 3A-C), even preceding the appearance of classic white matter plaques in some MS patients [21,27]. The majority of all cortical lesion types in early MS are highly inflammatory with intense myelin-laden macrophages (Figure 3D) and lymphocytic (Figure 3E-F) infiltrates similarly to active white matter lesions [21,27]. Lymphocytes, macrophages and microglia are seen in

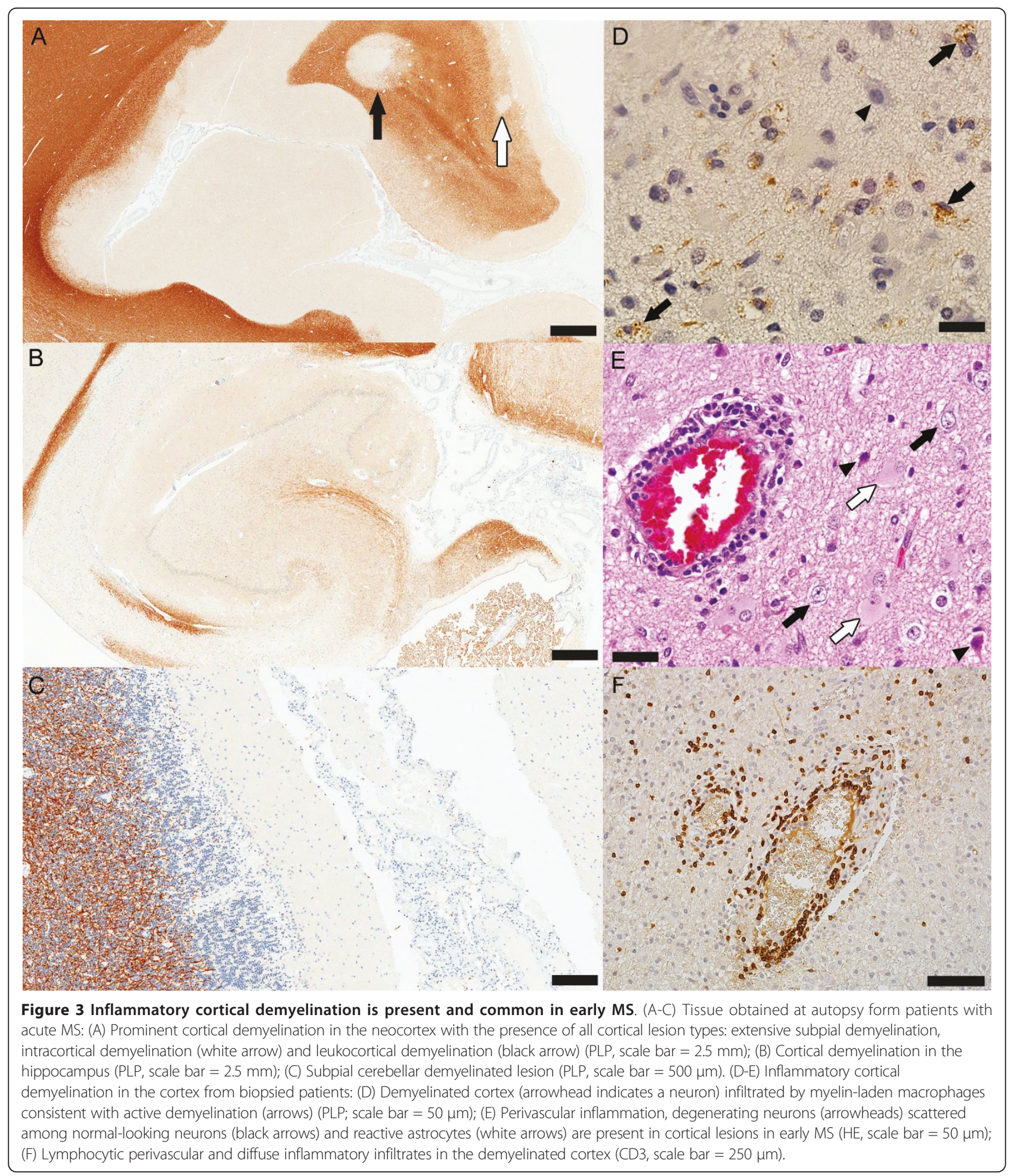


close apposition to neurons and neurites, suggesting a direct role of the inflammatory cells in neuronal damage (Figure 3E) [21,27]. All these differences can be explained by different lesional stages and suggest that the non-inflammatory character of chronic cortical demyelination may relate to long intervals between lesion formation and autopsy [47]. Similarly to chronic plaques, cortical lesions in early MS also show loss of oligodendrocyte, and axonal and neuronal injury (Figure $3 \mathrm{E})$ most likely the result of the acute inflammatory insult $[21,27]$. The presence of inflammatory cortical demyelination in early MS argues against a primary neurodegenerative process at this stage of disease. A recently developed rodent EAE model for cortical demyelination demonstrated that cortical inflammation is an early, transient and rapidly resolving phenomenon
[48]. Therefore, the rapid resolution of cortical inflammation may in part explain these apparent discordant findings with respect to the presence of inflammation in early versus chronic cortical demyelinating lesions. The fact that cortical demyelination is more extensive in progressive than early MS could be explained by the extremely fast and efficient remyelination of cortical lesions in early disease stages [49].

Meningeal inflammation is prominent not only in chronic MS, but also in early MS. Both focal perivascular meningeal inflammation and diffuse meningeal inflammation are topographically, significantly and strongly associated with cortical lesions in early MS (Figure 4) [21]. By analogy with observations made in experimental autoimmune encephalomyelitis [50-52], it is plausible that early meningeal inflammation in MS,

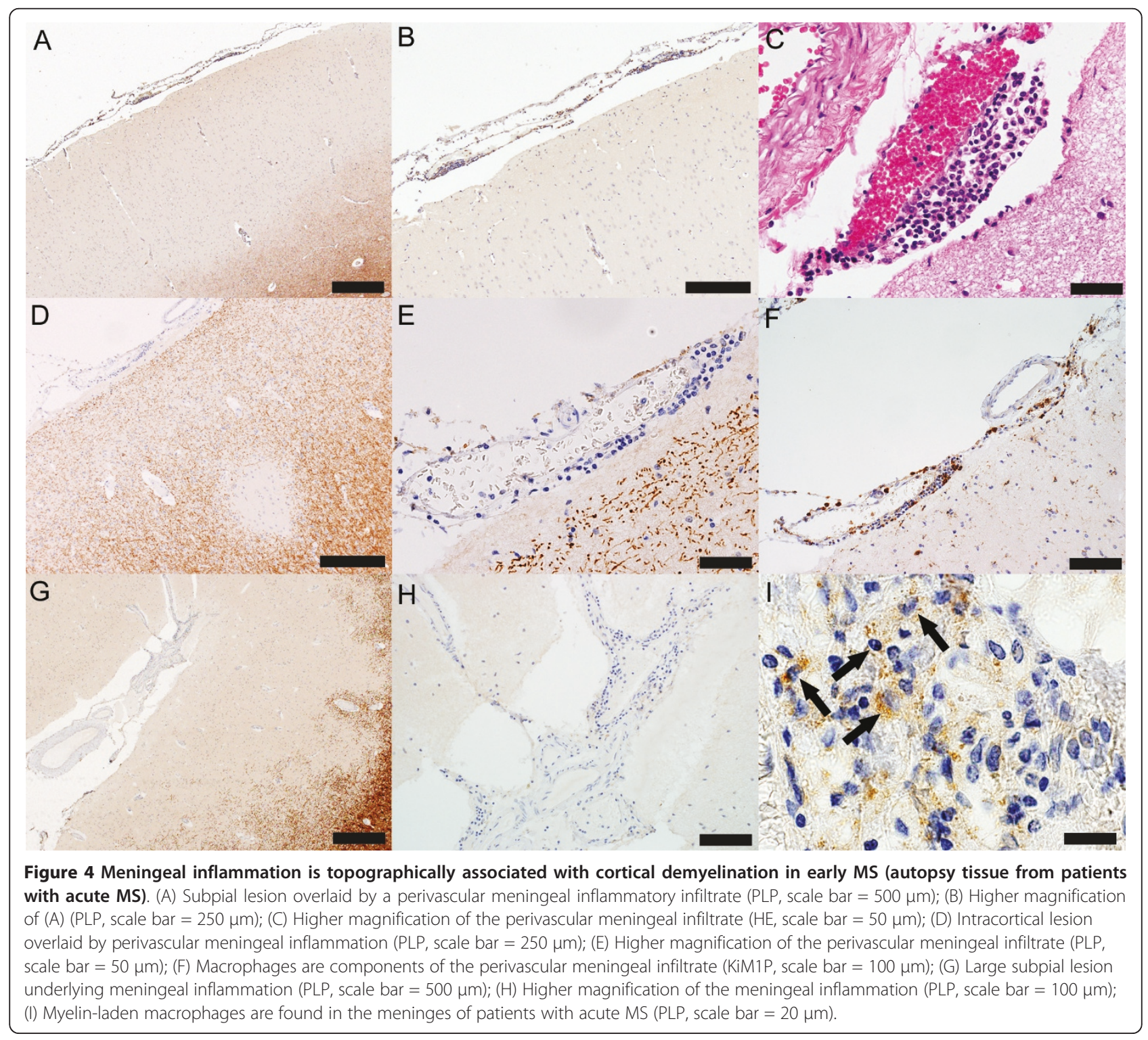


accompanied by inflammatory cytokine production in the subarachnoid space, could not only drive cortical demyelination, but also set the stage for subsequent subcortical white matter inflammation and demyelination [21].

\section{Conclusion}

Although very prominent in chronic progressive MS $[4,15,16,18]$, pathological and MRI evidence show that cortical demyelinated lesions are also present and common in early MS, and may be driven by meningeal inflammation $[18,21,27,41,43-45]$. Their inflammatory character suggests that neurodegeneration in MS runs on a background of inflammation [21,27]. Moreover, inflammatory cortical lesions may precede the appearance of classic white matter plaques at MS onset emphasizing the importance of considering demyelinating disease in the differential diagnosis of patients presenting with a solitary cortical enhancing lesion on MRI [27,41].

Although pathology has played a major role in understanding the pathophysiology of cortical demyelination, it is clear that the evolution of cortical lesions cannot be entirely understood from only one snapshot in the lesion's development that pathology offers. Conventional MRI techniques are not sensitive to detect intracortical and subpial lesions, but more recent imaging protocols using double inversion recovery and high field MRI have substantially improved their in vivo detection [53-57], and, without a doubt, will play, alongside pathology, a major role in fully elucidating the contribution of cortical demyelination to MS pathogenesis.

\section{Acknowledgements \\ Supported by grants from the National Multiple Sclerosis Society (NMSS RG3185-B-3, to Dr. Lucchinetti), the National Institutes of Health (1R01NS049577, to Dr. Lucchinetti) and the Saskatchewan Health Research Foundation (2633, to Dr. Popescu).}

\section{Author details \\ 'Department of Anatomy and Cell Biology, University of Saskatchewan, 107 Wiggins Road, Saskatoon, SK S7N 5E5, Canada. ${ }^{2}$ Cameco MS Neuroscience Research Center, Saskatoon City Hospital, 701 Queen Street, Saskatoon, SK S7K 0M7, Canada. ${ }^{3}$ Department of Neurology, Mayo Clinic, 200 First Street SW, Rochester, MN 55905, USA.}

\section{Authors' contributions \\ Both authors were involved in designing, writing, and editing the manuscript, and reviewed and fully approved the final version of the manuscript for submission.}

\section{Competing interests}

Dr. Popescu declares that he has no competing interests. Dr. Lucchinetti is listed as author and receives royalties for patent re: Aquaporin-4 associated antibodies for diagnosis of neuromyelitis optica; receives royalties from the publication of Blue Books of Neurology: Multiple Sclerosis 3 (Saunders Elsevier, 2010).

Received: 17 October 2011 Accepted: 7 March 2012 Published: 7 March 2012

\section{References}

1. Anderson DW, Ellenberg JH, Leventhal CM, Reingold SC, Rodriguez M, Silberberg DH: Revised estimate of the prevalence of multiple sclerosis in the United States. Ann Neurol 1992, 31(3):333-336.

2. Charcot JM: Lecture VI. Disseminated Sclerosis. Pathological Anatomy. Lectures on the Diseases of the Nervous System London: The New Sydenham Society; 1887, 157-181.

3. Sobel RA, Moore GRW: Demyelinating diseases. In Greenfield's Neuropathology. Volume 2, 8th edition. Edited by: Love S, Louis DN, Ellison DW. Oxford University Press; 2008:1513-1608

4. Peterson JW, Bo L, Mork S, Chang A, Trapp BD: Transected neurites, apoptotic neurons, and reduced inflammation in cortical multiple sclerosis lesions. Ann Neurol 2001, 50(3):389-400.

5. Brownell $B$, Hughes JT: The distribution of plaques in the cerebrum in multiple sclerosis. J Neurol Neurosurg Psychiatry 1962, 25:315-320.

6. Lumsden CE: The neuropathology of multiple sclerosis. In Multiple sclerosis and other demyelinating diseases. Volume 9. Edited by: Vinken PJ, Bruyn GW. Amsterdam. North Holland; 1970 .

7. Amato MP, Bartolozzi ML, Zipoli V, Portaccio E, Mortilla M, Guidi L, Siracusa G, Sorbi S, Federico A, De Stefano N: Neocortical volume decrease in relapsing-remitting MS patients with mild cognitive impairment. Neurology 2004, 63(1):89-93.

8. Barkhof F: The clinico-radiological paradox in multiple sclerosis revisited. Current opinion in neurology 2002, 15(3):239-245.

9. Lazeron $\mathrm{RH}$, Langdon DW, Filippi M, van Waesberghe $\mathrm{JH}$, Stevenson VL, Boringa JB, Origgi D, Thompson AJ, Falautano M, Polman $\mathrm{CH}$, et al: Neuropsychological impairment in multiple sclerosis patients: the role of (juxta)cortical lesion on FLAIR. Mult Scler 2000, 6(4):280-285.

10. Moriarty DM, Blackshaw AJ, Talbot PR, Griffiths HL, Snowden JS, Hillier VF, Capener S, Laitt RD, Jackson A: Memory dysfunction in multiple sclerosis corresponds to juxtacortical lesion load on fast fluid-attenuated inversion-recovery MR images. AJNR Am J Neuroradiol 1999, 20(10):1956-1962.

11. Rao SM, Leo GJ, Bernardin L, Unverzagt F: Cognitive dysfunction in multiple sclerosis. I. Frequency, patterns, and prediction. Neurology 1991, 41(5):685-691.

12. Rovaris M, Filippi M, Minicucci L, lannucci G, Santuccio G, Possa F, Comi G: Cortical/subcortical disease burden and cognitive impairment in patients with multiple sclerosis. AJNR Am J Neuroradio/ 2000, 21(2):402-408.

13. Sokic DV, Stojsavljevic N, Drulovic J, Dujmovic I, Mesaros S, Ercegovac M, Peric V, Dragutinovic G, Levic Z: Seizures in multiple sclerosis. Epilepsia 2001, 42(1):72-79.

14. Spatt J, Chaix R, Mamoli B: Epileptic and non-epileptic seizures in multiple sclerosis. J Neurol 2001, 248(1):2-9.

15. Bo L, Vedeler CA, Nyland H, Trapp BD, Mork SJ: Intracortical multiple sclerosis lesions are not associated with increased lymphocyte infiltration. Mult Scler 2003, 9(4):323-331.

16. Bo L, Vedeler CA, Nyland HI, Trapp BD, Mork SJ: Subpial demyelination in the cerebral cortex of multiple sclerosis patients. J Neuropathol Exp Neurol 2003, 62(7):723-732.

17. Kidd D, Barkhof F, McConnell R, Algra PR, Allen IV, Revesz T: Cortical lesions in multiple sclerosis. Brain 1999, 122(Pt 1):17-26.

18. Kutzelnigg A, Lucchinetti CF, Stadelmann C, Bruck W, Rauschka H, Bergmann M, Schmidbauer M, Parisi JE, Lassmann H: Cortical demyelination and diffuse white matter injury in multiple sclerosis. Brain 2005, 128(Pt 11):2705-2712.

19. Richert ND, Ostuni JL, Bash CN, Duyn JH, McFarland HF, Frank JA: Serial whole-brain magnetization transfer imaging in patients with relapsingremitting multiple sclerosis at baseline and during treatment with interferon beta-1b. AJNR Am J Neuroradio/ 1998, 19(9):1705-1713.

20. Wegner C, Esiri MM, Chance SA, Palace J, Matthews PM: Neocortica neuronal, synaptic, and glial loss in multiple sclerosis. Neurology 2006, 67(6):960-967.

21. Lucchinetti CF, Popescu BFG, Bunyan RF, Moll NM, Roemer SF, Lassmann H, Wolfgang B, Parisi JE, Scheithauer BW, Giannini C, et al: Inflammatory Cortical Demyelination in Early Multiple Sclerosis. N Engl J Med 2011, 365(23):2188-2197.

22. Duvernoy HM, Risold PY: The circumventricular organs: an atlas of comparative anatomy and vascularization. Brain Res Rev 2007, 56(1):119-147 
23. Geurts JJ, Bo L, Roosendaal SD, Hazes T, Daniels R, Barkhof F, Witter MP, Huitinga I, van der Valk P: Extensive hippocampal demyelination in multiple sclerosis. J Neuropathol Exp Neurol 2007, 66(9):819-827.

24. Huitinga I, De Groot CJ, Van der Valk P, Kamphorst W, Tilders FJ, Swaab DF: Hypothalamic lesions in multiple sclerosis. J Neuropathol Exp Neurol 2001, 60(12):1208-1218.

25. Kutzelnigg A, Faber-Rod JC, Bauer J, Lucchinetti CF, Sorensen PS, Laursen H, Stadelmann C, Bruck W, Rauschka H, Schmidbauer M, et al: Widespread demyelination in the cerebellar cortex in multiple sclerosis. Brain Pathol 2007, 17(1):38-44.

26. Papadopoulos D, Dukes S, Patel R, Nicholas R, Vora A, Reynolds R: Substantial archaeocortical atrophy and neuronal loss in multiple sclerosis. Brain Pathol 2009, 19(2):238-253.

27. Popescu BF, Bunyan RF, Parisi JE, Ransohoff RM, Lucchinetti CF: A case of multiple sclerosis presenting with inflammatory cortical demyelination. Neurology 2011, 76(20):1705-1710.

28. Bunyan RF, Popescu BF, Carter JL, Caselli RJ, Parisi JE, Lucchinetti CF: Childhood-onset multiple sclerosis with progressive dementia and pathological cortical demyelination. Arch Neurol 2011, 68(4):525-528.

29. Gilmore CP, Donaldson I, Bo L, Owens T, Lowe J, Evangelou N: Regional variations in the extent and pattern of grey matter demyelination in multiple sclerosis: a comparison between the cerebral cortex, cerebellar cortex, deep grey matter nuclei and the spinal cord. I Neurol Neurosurg Psychiatry 2009, 80(2):182-187.

30. Vercellino M, Plano F, Votta B, Mutani R, Giordana MT, Cavalla P: Grey matter pathology in multiple sclerosis. J Neuropathol Exp Neurol 2005, 64(12):1101-1107.

31. Magliozzi R, Howell O, Vora A, Serafini B, Nicholas R, Puopolo M, Reynolds R, Aloisi F: Meningeal B-cell follicles in secondary progressive multiple sclerosis associate with early onset of disease and severe cortical pathology. Brain 2007, 130(Pt 4):1089-1104.

32. Serafini B, Rosicarelli B, Magliozzi R, Stigliano E, Aloisi F: Detection of ectopic B-cell follicles with germinal centers in the meninges of patients with secondary progressive multiple sclerosis. Brain Pathol 2004, 14(2):164-174.

33. Serafini B, Rosicarelli B, Franciotta D, Magliozzi R, Reynolds R, Cinque $P$, Andreoni L, Trivedi P, Salvetti M, Faggioni A, et al: Dysregulated EpsteinBarr virus infection in the multiple sclerosis brain. J Exp Med 2007, 204(12):2899-2912.

34. Torkildsen O, Stansberg C, Angelskar SM, Kooi EJ, Geurts JJ, van der Valk P, Myhr KM, Steen VM, Bo L: Upregulation of immunoglobulin-related genes in cortical sections from multiple sclerosis patients. Brain Pathol 2010, 20(4):720-729.

35. Willis SN, Stadelmann C, Rodig SJ, Caron T, Gattenloehner S, Mallozzi SS, Roughan JE, Almendinger SE, Blewett MM, Bruck W, et al: Epstein-Barr virus infection is not a characteristic feature of multiple sclerosis brain. Brain 2009, 132(Pt 12):3318-3328.

36. Howell OW, Reeves CA, Nicholas R, Carassiti D, Radotra B, Gentleman SM, Serafini B, Aloisi F, Roncaroli F, Magliozzi R, et al: Meningeal inflammation is widespread and linked to cortical pathology in multiple sclerosis. Brain 2011, 134(Pt 9):2755-2771.

37. Cifelli A, Arridge M, Jezzard P, Esiri MM, Palace J, Matthews PM: Thalamic neurodegeneration in multiple sclerosis. Ann Neurol 2002, 52(5):650-653.

38. Simon JH, Kinkel RP, Jacobs L, Bub L, Simonian N: A Wallerian degeneration pattern in patients at risk for MS. Neurology 2000, 54(5):1155-1160

39. Bo L, Geurts JJ, van der Valk P, Polman C, Barkhof F: Lack of correlation between cortical demyelination and white matter pathologic changes in multiple sclerosis. Arch Neurol 2007, 64(1):76-80.

40. Vrenken H, Pouwels PJ, Geurts JJ, Knol DL, Polman CH, Barkhof F, Castelijns JA: Altered diffusion tensor in multiple sclerosis normalappearing brain tissue: cortical diffusion changes seem related to clinical deterioration. J Magn Reson Imaging 2006, 23(5):628-636.

41. Calabrese M, Gallo P: Magnetic resonance evidence of cortical onset of multiple sclerosis. Mult Scler 2009, 15(8):933-941.

42. De Stefano N, Matthews PM, Filippi M, Agosta F, De Luca M, Bartolozzi ML, Guidi L, Ghezzi A, Montanari E, Cifelli A, et al: Evidence of early cortical atrophy in MS: relevance to white matter changes and disability. Neurology 2003, 60(7):1157-1162.

43. Calabrese M, De Stefano N, Atzori M, Bernardi V, Mattisi I, Barachino L, Morra A, Rinaldi L, Romualdi C, Perini $P$, et al: Detection of cortical inflammatory lesions by double inversion recovery magnetic resonance imaging in patients with multiple sclerosis. Arch Neurol 2007,

64(10):1416-1422.

44. Calabrese M, Agosta F, Rinaldi F, Mattisi I, Grossi P, Favaretto A, Atzori M, Bernardi V, Barachino L, Rinaldi L, et al: Cortical lesions and atrophy associated with cognitive impairment in relapsing-remitting multiple sclerosis. Arch Neurol 2009, 66(9):1144-1150.

45. Calabrese M, Grossi P, Favaretto A, Romualdi C, Atzori M, Rinaldi F, Perini P, Saladini M, Gallo P: Cortical pathology in multiple sclerosis patients with epilepsy: a 3 year longitudinal study. J Neurol Neurosurg Psychiatry 2011.

46. Sharma R, Narayana PA, Wolinsky JS: Grey matter abnormalities in multiple sclerosis: proton magnetic resonance spectroscopic imaging Mult Scler 2001, 7(4):221-226.

47. Popescu BF, Bunyan RF, Parisi JE, Ransohoff RM, Lucchinetti C: A Case of Multiple Sclerosis Presenting with Inflammatory Cortical Demyelination. Neurology 2011, 76(20):1705-10.

48. Merkler D, Ernsting T, Kerschensteiner M, Bruck W, Stadelmann C: A new focal EAE model of cortical demyelination: multiple sclerosis-like lesions with rapid resolution of inflammation and extensive remyelination. Brain 2006, 129(Pt 8):1972-1983.

49. Albert M, Antel J, Bruck W, Stadelmann C: Extensive cortical remyelination in patients with chronic multiple sclerosis. Brain Pathol 2007, 17(2):129-138.

50. Brown DA, Sawchenko PE: Time course and distribution of inflammatory and neurodegenerative events suggest structural bases for the pathogenesis of experimental autoimmune encephalomyelitis. J Comp Neurol 2007, 502(2):236-260.

51. Lassmann H, Wisniewski HM: Chronic relapsing EAE. Time course of neurological symptoms and pathology. Acta Neuropathol 1978, 43(12):35-42.

52. Weller RO, Engelhardt B, Phillips MJ: Lymphocyte targeting of the central nervous system: a review of afferent and efferent CNS-immune pathways. Brain Pathol 1996, 6(3):275-288.

53. Calabrese M, Filippi M, Gallo P: Cortical lesions in multiple sclerosis. Nature reviews Neurology 2010, 6(8):438-444.

54. Filippi M, Rocca MA: Novel MRI approaches to assess patients with multiple sclerosis. Current opinion in neurology 2010, 23(3):212-217.

55. Geurts JJ, Barkhof F: Grey matter pathology in multiple sclerosis. Lancet Neurol 2008, 7(9):841-851.

56. Pirko I, Lucchinetti CF, Sriram S, Bakshi R: Gray matter involvement in multiple sclerosis. Neurology 2007, 68(9):634-642.

57. Schmierer K, Parkes HG, So PW, An SF, Brandner S, Ordidge RJ, Yousry TA, Miller DH: High field (9.4 Tesla) magnetic resonance imaging of cortical grey matter lesions in multiple sclerosis. Brain 2010, 133(Pt 3):858-867.

Pre-publication history

The pre-publication history for this paper can be accessed here: http://www.biomedcentral.com/1471-2377/12/11/prepub

doi:10.1186/1471-2377-12-11

Cite this article as: Gh Popescu and Lucchinetti: Meningeal and cortical grey matter pathology in multiple sclerosis. BMC Neurology 2012 12:11.

\section{Submit your next manuscript to BioMed Central and take full advantage of:}

- Convenient online submission

- Thorough peer review

- No space constraints or color figure charges

- Immediate publication on acceptance

- Inclusion in PubMed, CAS, Scopus and Google Scholar

- Research which is freely available for redistribution

Submit your manuscript at www.biomedcentral.com/submit
C Biomed Central 